\title{
The effect of metoprolol on plasma lipids
}

\author{
I. W. BeInART \\ M.B., M.R.C.P. \\ R. M. PeArson \\ M.B., M.R.C.P.
}

D. G. Cramp*

PH.D.
C. W. H. Havard
D.M., F.R.C.P.

Clinical Pharmacology Unit, Royal Northern Hospital, London, N.7

\begin{abstract}
Summary
Fifteen hypertensive patients entered a single-blind study to examine the effects of metoprolol $(100 \mathrm{mg}$ twice daily) on fasting plasma lipids. In 12 patients who completed the study, non-esterified fatty acid concentrations fell, but cholesterol and triglyceride levels were unchanged after 12 weeks' treatment. These results conflict with earlier reports of the effect of metoprolol on plasma triglyceride concentrations.
\end{abstract}

\section{Introduction}

$\beta$-adrenoreceptor blocking drugs have been reported as having various effects on basal plasma lipid levels. For example, the non-selective drug propranolol has been reported (Tanaka et al., 1976) as reducing plasma non-esterified fatty acids initially, and subsequently, after 7 weeks' treatment, as increasing their concentration. There is conflicting evidence (Waal-Manning, 1976; Nilsson, Hansson and Hökfelt, 1978) on the effect of the cardioselective $\beta$-adrenoreceptor blocking drug metoprolol on fasting plasma triglyceride concentrations. The present study was designed to observe the effects on fasting plasma lipid levels in hypertensive patients treated with metoprolol for a period of 12 weeks and subsequently to observe the changes over 4 weeks after the withdrawal of treatment.

\section{Patients and methods}

Fifteen out-patients ( 8 male) with uncomplicated essential hypertension were selected for the study. Their ages ranged from 31 to 67 (mean 47) years, and their average blood pressure at the start of the study before treatment with metoprolol was 159/104 mmHg. Eight patients were newly diagnosed and had not received any treatment for hypertension before the study. Of the remaining 7, 4 had previously been treated with a combination of propranolol and bendrofluazide, 2 with hydrallazine and one had

*Department of Chemical Pathology, Royal Free Hospital, London, N.W.3. been treated with methyldopa. No patient had a history of angina, myocardial infarction, heart failure, stroke or asthma. All patients had grade I or II hypertensive fundal changes and a plasma urea of less than $10 \mathrm{mmol} / \mathrm{l}$. The study was approved by the hospital's ethics committee and informed consent recorded for each patient.

\section{Design of the study}

The study was of single-blind design with 3 treatment periods. Before the study proper there was a run-in period of 4 weeks when no medication was given. In the first treatment period patients received a placebo for 4 weeks. The treatment in the second period was metoprolol $100 \mathrm{mg}$ twice daily and this was continued for 12 weeks. In the third and final period, placebo was again administered for 4 weeks. The placebo and active drugs were identical in appearance and the times of administration were the same.

Patients were seen at 2-weekly intervals. At each visit blood pressure was measured with a Hawksley (random-zero) sphygmomanometer after resting for $3 \mathrm{~min}$ in the supine position. Diastolic blood pressure was recorded at the point of muffling of sound (Korotkoff IV). Blood pressure was measured by the same individual throughout the study. Pulse rate was measured after blood pressure had been recorded at each visit. The patient's weight and fundal appearance were noted.

Patients were told that blood chemistry would be examined at each visit but the fact that plasma lipids were to be studied was not revealed until after the study, in case patients chose to alter their diet and hence possibly influence the result of the study. For the same reason patients were not given advice on weight reduction or cigarette consumption until after completion of the study. At each visit, at a time 30 min after taking their morning medication, a small intravenous cannula (Abbot 21) was inserted into a forearm vein under local anaesthetic $(1 \%$ 
lignocaine) in each patient. After a further $30 \mathrm{~min}$ blood was drawn without cuff pressure for measurement of serum albumin (Northam and Widdowson, 1967) and globulin (Autoanalyser Methods), plasma cholesterol (Robertson and Cramp, 1970), triglyceride (Cramp and Robertson, 1968) and non-esterified fatty acid (Carruthers and Young, 1973) concentrations. At the end of each treatment period blood was also taken for haematological and biochemical tests (haemoglobin, white cell count; serum bilirubin, aspartate transaminase and alkaline phosphatase; plasma sodium, potassium and urea). Patients were instructed to take only water from $11.00 \mathrm{pm}$ on the evening before attending the clinic. They were asked not to smoke any tobacco or consume any alcohol on the evening before their attendance in the clinic. Tablet containers were collected at each visit, their contents discreetly counted and new tablets issued. A symptom enquiry was performed at each visit.

Criteria for withdrawal from the study were established before it began and were: (1) troublesome symptomatic side effects; (2) unacceptable blood pressures - defined as lying diastolic blood pressure above $120 \mathrm{mmHg}$ on 2 successive visits; (3) deterioration of cardiac, renal, respiratory or hepatic function; (4) development of angina, myocardial infarction or stroke; (5) failure to adhere to the regime.

\section{Statistical analysis}

The Scheffe (1953) test was used to compare the average values obtained in the metoprolol treatment period with the average values obtained during the placebo periods. A 2-tailed $t$ test was used to compare data at particular times in the treatment period with the corresponding values obtained at the end of the first placebo period. A $P$ value of $<0.05$ was accepted to refute the null hypothesis.

\section{Results}

Twelve patients completed the study. One was withdrawn because of persistent bradycardia while receiving metoprolol and 2 patients failed to adhere to the protocol. All data from the remaining patients were available for analysis.

The mean blood pressure and pulse rate at the end of the first placebo period were $159 / 104 \mathrm{mmHg}$ and $75 / \mathrm{min}$ respectively. At the end of the metoprolol treatment period these readings fell significantly to $127 / 83 \mathrm{mmHg}$ and $60 / \mathrm{min}$ respectively (Table 1 ). The mean plasma triglyceride concentration was unchanged at $1.3 \mathrm{mmol} / \mathrm{l}$ in each of the 3 treatment periods.

The mean plasma non-esterified fatty acid concentration fell significantly at 2 weeks after metoprolol was introduced from 760 to $553 \mu \mathrm{mol} / \mathrm{l}$, and this fall
TABLE 1. Physiological and biochemical effects of metoprolol (12 patients)

\begin{tabular}{|c|c|c|c|}
\hline $\begin{array}{l}\text { Day } \\
\text { Treatment }\end{array}$ & $\begin{array}{c}28 \\
\text { Placebo }\end{array}$ & $\begin{array}{c}112 \\
\text { Metoprolol }\end{array}$ & $\begin{array}{c}140 \\
\text { Placebo }\end{array}$ \\
\hline Blood pressure $(\mathrm{mmHg})$ & $159 / 104$ & $127^{*} / 83^{*}$ & $149 / 99$ \\
\hline Pulse (beats/min) & 75 & $60 \dagger$ & 70 \\
\hline $\begin{array}{l}\text { Non-esterified fatty acids } \\
\qquad(\mu \mathrm{mol} / 1)\end{array}$ & 760 & $553 \dagger$ & 788 \\
\hline Cholesterol (mmol/l) & $5 \cdot 8$ & $6 \cdot 3$ & $5 \cdot 9$ \\
\hline Triglycerides (mmol/l) & $1 \cdot 3$ & $1 \cdot 3$ & $1 \cdot 3$ \\
\hline Albumin $(g / l)$ & 41 & $38^{*}$ & 42 \\
\hline Globulin $(\mathrm{g} / \mathrm{l})$ & 23 & 24 & 22 \\
\hline
\end{tabular}

${ }^{*} P<0.05 \quad \dagger P<0.01$ compared with first placebo period

was consistent throughout the entire treatment period of 12 weeks. The levels rose to pre-treatment values 2 weeks after stopping metoprolol.

Cholesterol levels were slightly increased in the metoprolol treatment period but this increase did not attain statistical significance. There was a slight but significant fall in serum albumin concentration but globulin concentration was unaffected by metoprolol. Body weight of the patients was unchanged as were all of the other biochemical and haematological variables examined.

Two patients developed tiredness in the metoprolol treatment period which was not apparent in the placebo periods and was therefore thought to be related to metoprolol.

\section{Discussion}

There is currently much debate about whether $\beta$-adrenoreceptor blocking drugs or diuretics should be used as first-line treatment for moderate hypertension. The incidence of carbohydrate intolerance after diuretic therapy is significant (Breckenridge et al., 1967). Diuretics may be associated with a rise in serum cholesterol concentration (Ames and Hill, 1976). There is evidence that raised triglyceride concentrations increase the risk of cardiovascular death when they exceed $1.7 \mathrm{mmol} / 1$ irrespective of the cholesterol concentration (Pelkonen et al., 1977). Earlier studies (Waal-Manning, 1976) using similar doses of metoprolol to those employed in this study had shown that metoprolol increased plasma triglycerides. Clearly if this effect were to be confirmed it would provide a theoretical disadvantage for the use of metoprolol. It is not clear why there should be a discrepancy between the present study and that of Waal-Manning although it has been suggested (Nilsson et al., 1977, 1978) that such discrepancies might arise from different patient selection criteria. In a study in which patients were investigated under metabolic ward conditions (Nilsson et al., 1978), metoprolol was found not to affect fasting triglyceride levels nor those values for triglycerides obtained after food and exercise. Propranolol has 
also been reported as producing no change in triglyceride concentrations (Spottl, Holzknecht and Braunsteiner, 1968), but that study did show a reduction in free serum cholesterol at the end of 8 weeks' treatment.

Plasma non-esterified fatty acid concentrations have been shown to increase within $24 \mathrm{hr}$ of a myocardial infarction. In non-diabetic patients with myocardial infarction it was found (Spottl et al., 1968) that the plasma concentration of non-esterified fatty acids are significantly higher in those who subsequently develop ventricular fibrillation. Thus, a raised level of non-esterified fatty acids might be potentially harmful in hypertensive patients. Propranolol has been reported (Tanaka et al., 1976) as initially reducing and subsequently increasing nonesterified fatty acid concentrations, atenolol (Deacon, 1978) as reducing them, practolol (Ghosh, Cochrane and de Bono, 1975) as having no effect, while pindolol (Schlierf, Papenberg and Raetzer, 1973) as causing an increase. Metoprolol has previously been reported (Nilsson et al., 1978; Newman, 1977) as having no effect on plasma non-esterified fatty acid levels under basal conditions. The reason for the disparity between the findings in the present study and earlier reports is not clear.

Metoprolol caused a small but significant fall in the serum ablumin concentration. It is unlikely that this was due to a dilutional effect since the serum globulin concentration was not affected. A similar effect has been observed in a study on oxprenolol (Pearson et al., 1976). Non-esterified fatty acids are avidly bound to albumin (Goodman, 1958) but the relationship is a stoichiometric one. Thus, the reduction in serum albumin $(7 \%)$ would not account for the much larger $(27 \%)$ reduction in nonesterified fatty acids.

\section{Conclusion}

Metoprolol in doses which significantly reduce raised arterial blood pressure has no effect on plasma triglyceride or cholesterol concentrations, but causes a significant reduction in plasma nonesterified fatty acids. This may be of advantage in patients with risk factors for myocardial infarction including those with hypertension.

\section{References}

Ames, R.P. \& HiLl, P. (1976) Elevation of serum lipid levels during diuretic therapy of hypertension. American Journal of Medicine, 61, 748.
Autoanalyser Methods. An Autoanalyser Method for the Measurement of Serum Globulin. File N. 14B. Technicon Corporation.

Breckenridge, A., Welborn, T.A., Dollery, C.T. \& FRASER, F. (1967) Glucose tolerance in hypertensive patients on long-term diuretic therapy. Lancet, i, 61 .

Carruthers, M. \& Young, D.A.B. (1973) Free fatty acid estimation by a semi-automated fluorimetric method. Clinica chimica acta, 49, 341.

Cramp, D.G. \& Robertson, G. (1968) The fluorometric assay of triglyceride by semi-automated method. Analytical Biochemistry, 25, 246.

DEACON, S.P. (1978) The effects of atenolol and propranolol upon lipolysis. British Journal of Clinical Pharmacology, $5,123$.

Ghosh, P., Cochrane, A.M.G. \& DE Bono, D. (1975) Effects of long-term practolol therapy on plasma lipids after acute myocardial infarction. Lancet, i, 9.

Goodman, D.S. (1958) The interaction of human serum albumin with long-chain acid anions. Journal of the American Chemical Society, 80, 3892.

Newman, R.J. (1977) Comparison of the antilipolytic effect of metoprolol, acebutol and propranolol in man. British Medical Journal, 2, 601.

Nilsson, A., Hansson, B.G. \& Hökfelt, B. (1977) Betablockers and lipid metabolism. British Medical Journal, 2, 126.

Nilsson, A., Hansson, B.G. \& Hökfelt, B. (1978) Effect of metoprolol on blood glycerol, free fatty acids, triglycerides and glucose in relation to plasma catecholamines in hypertensive patients at rest following sub-maximal work. European Journal of Clinical Pharmacology, 13, 5.

NorthaM, B.E. \& Widdowson, G.S. (1967) Determination of serum albumin by auto-analyzer using bromocresol green. Association of Clinical Biochemists' Technical Bulletin, 11, 1.

Pearson, R.M., Bending, M.R., Bulpitt, C.J., George, C.F., Hole, D.R., Williams, F.M. \& Breckenridge, A.M. (1976) Trial of combination of guanethidine and oxprenolol in hypertension. British Medical Journal, 1, 933.

Pelkonen, R., Nikkila, E.A., Koskinen, S., Pentinnen, K. \& SARNA, S. (1977) Association of serum lipids and obesity with cardiovascular mortality. British Medical Journal, 2, 1185.

Robertson, G. \& Cramp, D.G. (1970) An evaluation o. cholesterol determination in serum and serum lipoprotein fractions by a semi-automated fluorimetric method. Journal of Clinical Pathology, 23, 243.

SCHEFFE, H.A. (1953) A method for judging all contrasts in the analysis of variance. Biometrika, 40, 87.

SChlierf, G., Papenberg, J \& Raetzer, H. (1973) The effect of 1-(indol-4-yl-oxy)-3-isopropylamine-propran-2-01 (LB-46, visken) on carbohydrate and lipid metabolism. European Journal of Clinical Pharmacology, 5, 154.

SPOTTL, F., HolzKNECHT, F. \& BRAUNSTEINER, H.J. (1968) Inhibitors of the plasminogen activation in patients with primary "carbohydrate-induced" hypertriglyceridemia. Atherosclerosis Research, 8, 821.

Tanaka, N., Sakaguchi, S., Oshige, K., Nimura, T. \& KANESHISA, T. (1976) Effect of chronic administration of propranolol on lipoprotein composition. Metabolism, 25, 1071.

WAal-Manning, H.J. (1976) Metabolic effects of betaadrenoreceptor blockers. Drugs, 11 (Suppl. 1), 121. 